\title{
Vision-related quality of life considering both eyes: results from the German population-based Gutenberg Health Study (GHS)
}

Stefan Nickels ${ }^{1 *}$ D, Alexander K. Schuster ${ }^{1}$, Heike Elflein ${ }^{1}$, Christian Wolfram¹, Andreas Schulz², Thomas Münzel ${ }^{3}$, Manfred E. Beutel ${ }^{4}$, Irene Schmidtmann ${ }^{5}$, Robert P. Finger ${ }^{6+}$ and Norbert Pfeiffer ${ }^{1+}$

\begin{abstract}
Purpose: Most definitions of visual impairment focus on the status of the better-seeing eye only, but this approach might underestimate the influence of the worse-seeing eye on the vision-related quality of life (VRQoL).

Methods: We assessed distance-corrected visual acuity in both eyes and VRQoL using the "National Eye Institute 25-Item Visual Function Questionnaire" (NEI VFQ-25) in the German population-based Gutenberg Health Study. We calculated the Rasch-based visual functioning scale (VFS) and socioemotional scale (SES). We categorized the visual acuity of the better-seeing eye (BE) and worse-seeing eye (WE) as follows: (1) no visual impairment (VI) $(<0.32$ $\log M A R)$ ), (2) mild $\mathrm{VI}(0.32-0.5 \log M A R)$, and (3) moderate to severe $\mathrm{VI}(>0.5 \log M A R)$. Next, the subjects were categorized as follows: both eyes with no $\mathrm{VI}$ (no/no), the better-seeing eye with no $\mathrm{VI}$ and the worse-seeing eye with mild $\mathrm{VI}$ (no/mild), no VI/severe VI (no/severe), both eyes with mild $\mathrm{VI}$ (mild/mild), light $\mathrm{VI} /$ severe $\mathrm{VI}$ (mild/ severe), and both eyes with severe VI (severe/severe). We calculated the median scores for VFS and SES. We used linear regression to estimate the combined influence of BE/WE on VFS and SES.
\end{abstract}

Results: We included 11,941 participants (49.9\% female, age range: 35-74 years) with information on VRQoL and visual acuity. The median VFS/SES scores were 90/100 (no/no VI group), 84/97 (no/mild group), 81/94 (no/severe group), 70/90 (mild/mild group), 67/74 (mild/severe group), and 63/76 (severe/severe group). These differences were supported by the regression analysis results.

Conclusion: Relying on the function of the better-seeing eye considerably underestimates the impact of visual impairment on VRQoL.

\section{Background}

The assessment of visual impairment poses the analytical challenge that both eyes could be affected differently. Most common definitions of visual impairment meet this challenge by focusing on the visual function of the better-seeing eye only -e.g., the definition of blindness of

\footnotetext{
* Correspondence: post@stefan-nickels.de

Some of the results have been presented as talks at the 116th DOG

Congress (Bonn, Germany, 27. 30 September 2018), and at the ARVO 2019

Annual Meeting (28 April - 2 May 2019, Vancouver, Canada)

${ }^{\dagger}$ Robert P. Finger and Norbert Pfeiffer contributed equally to this work.

'Department of Ophthalmology, University Medical Center of the Johannes

Gutenberg-University Mainz, Langenbeckstr. 1, 55131 Mainz, Germany

Full list of author information is available at the end of the article
}

the World Health Organization and Global Burden of Disease Study $[1,2]$. However, there is increasing evidence that this approach underestimates the influence of the worse-seeing fellow eye on visual function and vision-related quality of life (VRQoL) [3, 4]. The Melbourne Visual Impairment Project showed that even unilateral vision loss caused difficulties in reading and recognizing faces and increased the risk of falling when away and becoming dependent in persons aged 40 years and older [5]. Additionally, there is evidence from outcome studies that patients who underwent cataract surgery in both eyes reported greater improvement in quality of life than patients who underwent surgery in only one eye [6,7]. Studies in patients 
with age-related macular degeneration showed that bilateral manifestation is associated with lower VRQoL than unilateral manifestation [8]. Finger et al. showed that calculating patient reported utilizes based on the better-seeing eye only is likely to underestimate the impact of visual impairment [4]. To further elucidate the contribution of both eyes to VRQoL, we explored in a large populationbased sample whether VRQoL is different when stratifying participants according to the visual acuity of their better-seeing eye only and compared this to also considering the visual acuity of the fellow eye (e.g., the worse-seeing eye). We hypothesize that there will be a substantial impact of the worse-seeing eye on VRQoL.

\section{Materials and methods}

\section{Study population}

We analyzed a subsample of the Gutenberg Health Study (GHS) with data on both visual acuity and VRQoL available. The GHS is a population-based, single-center, prospective, cohort study at the medical center of the Johannes Gutenberg University Mainz in Germany [9]. The population sample was randomly drawn via local residents' registration offices and equally stratified by sex for each decade of age. The baseline examination included 15,010 participants aged 35 to 74 years and was conducted from 2007 to 2012. The examination consisted of an ophthalmological examination, general and cardiovascular examinations, and questionnaires and interviews. The ophthalmic branch has been described in detail by Höhn et al. [10]. Briefly, we conducted measurements of autorefraction and distance-corrected visual acuity, intraocular pressure, visual field testing, pachy- and keratometry, and posterior segment photography. We used the NEI VFQ-25 to assess VRQoL. We included all participants who completed this questionnaire and with available information on the visual acuity of both eyes.

\section{VRQoL data acquisition and analysis}

Vision-related QoL was assessed using the German version of the NEI VFQ-25 [11, 12]. The German NEI VFQ-25 has been assessed for its psychometric properties and was used by various studies [12-17]. The questionnaire was self-administered as a print-out at the study site and completed using both eyes and reading glasses, if necessary. We used the most common VRQoL instrument and applied state-of-the-art techniques remediating the known flaws-i.e., the violation of unidimensionality and lack of interval-scaled measurementsto analyze the NEI VFQ-25 data. We followed the suggestions of Pesudovs to calculate the "visual functioning scale (VFS)" and "socioemotional scale" (SES); both are interval scaled $(0=$ worst to $100=$ best $)$ and based on the Rasch-transformed individual-level NEI VFQ-25 data $[18,19]$. The developers of the questionnaire initially proposed to calculate 12 subscores and one composite VRQoL score (http://www.rand.org/health/surveys_tools/ vfq.html, last accessed 2018-03-27) [18]. Subsequent studies showed that this approach violates unidimensionality and interval-level measurement, both important properties of an instrument measuring QoL [20-24]. Therefore, we chose the Rasch-based approach described above, as previously used by us and others $[18,19,25,26]$.

\section{Ocular measurements}

Objective refraction and distance-corrected visual acuity were measured in both eyes using a Humphrey Automated Refractor/Keratometer (HARK) 599 (Carl Zeiss AG, Jena, Germany) without cycloplegia, starting with the right eye [10]. Distance-corrected visual acuity was measured using the built-in Snellen charts, ranging from $20 / 400$ to $40 / 20$ ( $\log$ MAR 1.3 to -0.3 ). Below that visual acuity, we used a visual acuity chart at a distance of one meter up to 20/800 (logMAR 1.6), followed by counting fingers, hand movements, and the light perception test. The spherical equivalent was calculated as the spherical correction value plus half of the cylindrical power. A history of eye disease was assessed in a short interview preceding the eye examination.

\section{Sociodemographic characteristics}

The socioeconomic status was based on income, education and occupation and was defined according to the German Health Update 2009 (GEDA), with a range from 3 (lowest) to 21 (highest) socioeconomic status [27].

\section{Statistical analysis}

For descriptive analyses, we calculated the mean of the spherical equivalent of both eyes for every participant. Visual acuity measurements were converted to $\log$ MAR [28]. We categorized the visual acuity of the better-seeing eye and worse-seeing eye as follows, with the thresholds based on the WHO definition of visual impairment (VI): (0) no VI $(<0.32 \log \mathrm{MAR}))$, (1) mild VI (0.32-0.5 logMAR), and (2) moderate to severe VI ( $>0.5 \log$ MAR) [1, 4]. The subjects were then categorized in 6 groups according to the VI categories of both eyes (Table 1).

We calculated the median and interquartile range for both VFS and SES for each group. We used linear regression models to estimate the influence of the combination of BE/WE on the VRQoL scores (reference group: no visual impairment in both eyes). We adjusted for age and sex in the basic model and additionally for socioeconomic status in a second model. Additionally, we calculated separate models for participants aged younger than 65 years and those aged 65 years and older. We repeated the analyses restricted to participants without self-reported amblyopia. Amblyopia is characterized by reduced vision since childhood and might have a different impact on 
Table 1 Cross-table illustrating the categorization of subjects according to visual impairment of both eyes in the populationbased Gutenberg Health Study (2007-2012)

\begin{tabular}{lllll}
\hline & & \multicolumn{2}{l}{ Worse-seeing eye: } \\
\cline { 3 - 4 } & & No VI & Mild VI & $\begin{array}{l}\text { Moderate/ } \\
\text { severe }\end{array}$ \\
\hline Better- & No Vl & "b0/w0", $n=$ & "b0/w1", & "b0/w2", \\
seeing eye: & & 11,021 & $n=430$ & $n=395$ \\
& Mild VI & $/$ & "b1/w1", & "b1/w2", \\
& & & $n=35$ & $n=34$ \\
& Moderate/ & $/$ & $/$ & "b2/w2", \\
& severe Vl & & & $n=26$ \\
\hline
\end{tabular}

$B E$ Better-seeing eye, WE Worse-seeing eye, VI Vision impairment; no VI: $<0.32$ $\log M A R$, mild VI: 0.32-0.5 logMAR; moderate/severe VI: > $0.5 \log M A R$

VRQoL than visual impairment acquired in later life as affected persons are used to having "one lazy eye" (i.e., only one functioning eye) [29]. The VRQoL might additionally be affected by other nonocular chronic diseases. Therefore, we also calculated models restricted to participants without the following chronic diseases: diabetes mellitus, cardiovascular disease, peripheral artery disease, chronic kidney disease, chronic liver disease, chronic obstructive pulmonary disease, depression, and cancer. Due to the exploratory character of this analysis, $p$-values were not adjusted for multiple testing. The data were analyzed using GNU R version 3.3.1 [30].

\section{Results}

Our sample consisted of 11,941 GHS participants (49.9\% female; median age: 54.7 years) who completed the questionnaire without missing items necessary to calculate the VRQoL scales and with visual acuity of both eyes available. Categorized by the better-seeing eye, $n=$ $11,846(99.2 \%)$ had no VI, $n=69(0.6 \%)$ had mild VI, and $n=26(0.2 \%)$ had moderate to severe VI. The median VRQoL score of the visual functioning scale (VFS) was 89.6 and that of the socioemotional scale (SES) was 100.0. Details of the study sample are shown in Table 2. Characteristics stratified by sex are shown in the (Additional file 1: Table S1).

Categorized only by the better eye, the median scores for the VFS were 89.6 (no VI), 70.2 (mild VI), and 63.2 (moderate to severe VI) (Table 3). If the VI of the worse-seeing eye was considered additionally, there was a decrease of approximately four points per VI category in the strata defined by the better-seeing eye (Tables 4 and 5 , Fig 1). Participants with no visual impairment in the better-seeing eye and mild visual impairment in the fellow eye had a 5.0-point lower VFS score than participants with no visual impairment in both eyes (95\% confidence interval (CI) -6.0; - 4.1). Participants with no visual impairment in the better-seeing eye and severe visual impairment in the fellow eye had a 9.0-point lower VFS score than participants with no visual impairment in both eyes $(95 \% \mathrm{CI}$ :
Table 2 Characteristics of the study sample of the German population-based Gutenberg Health Study (GHS) with visual acuity of both eyes and NEI VFQ-25 data available

\begin{tabular}{ll}
\hline & All \\
\hline Age [y] & 11,941 \\
Women & $54.7(11.1)$ \\
Socioeconomic status & $49.9 \%(5958)$ \\
Eye characteristics: & $13.1(4.4)$ \\
Mean spherical equivalent [dpt] & \\
Visual acuity (better eye) [logMAR] & $-0.12(-1.25 / 0.81)$ \\
Visual acuity (worse eye) [logMAR] & $0(0 / 0.10)$ \\
Contact lenses or glasses & $0(0 / 0.22)$ \\
Distance glasses & $89.2 \%(10646)$ \\
History of eye surgery & $68.0 \%(8116)$ \\
Glaucoma & $7.3 \%(876)$ \\
Age-related macular degeneration & $2.3 \%(270)$ \\
Amblyopia & $0.4 \%(51)$ \\
Vision-related quality of life: & $9.9 \%(1186)$ \\
Visual functioning scale (NEI VFQ-25) & \\
Socioemotional scale (NEI VFQ-25) & $89.6(81.3 / 95.1)$ \\
\hline
\end{tabular}

Continuous variables were described by mean values and standard deviation, and a skewed distribution was described by the median and interquartile range. Discrete variables were described by relative and absolute frequencies.

$-10.0 ;-8.0)$. These estimates are from the regression model adjusted for age, sex and socioeconomic status (Table 6). Different adjustment sets or restrictions to a subsample without general comorbidities or amblyopia resulted in only minor changes in the estimates (Additional files 2, 3, 4, 5, 6 and 7). For all regression coefficients in the main analyses, $\mathrm{p}$ was below 0.0001 .

The median scores for the SES were 100 (no VI), 88.4 (mild VI), and 76.3 (moderate to severe VI) (Table 3). If the worse-seeing eye was considered additionally, there was a decrease of approximately three points per VI category in the stratum of no VI in the better-seeing eye (Tables 6 and 7, Fig. 2). In the stratum of the better-seeing eye with mild VI, there was a decrease of 16 points.

Table 3 NEI VFQ-25 visual functioning scale scores and socioemotional scale scores by categories of vision impairment of the better-seeing eye only in the German population-based Gutenberg Health Study (GHS), 2007-2012

\begin{tabular}{lll}
\hline $\begin{array}{l}\text { Visual impairment of the } \\
\text { better-seeing eye }\end{array}$ & $\begin{array}{l}\text { visual functioning } \\
\text { scale score (VFS) }\end{array}$ & $\begin{array}{l}\text { socioemotional } \\
\text { scale score (SES) }\end{array}$ \\
\hline No VI $(n=11,846)$ & $89.6(81.3 / 95.1)$ & $100(94.6 / 100)$ \\
Mild VI $(n=69)$ & $70.2(57.6 / 78.0)$ & $88.4(67.9 / 97.1)$ \\
Moderate/severe VI $(n=$ & $63.2(46.6 / 78.7)$ & $76.3(68.0 / 93.9)$ \\
26) & &
\end{tabular}

Scores displayed as medians (interquartile range); VI Vision impairment; no Vl: $<0.32$ logMAR, mild VI: 0.32-0.5 logMAR; moderate/severe VI: >0.5 logMAR 
Table 4 NEI VFQ-25 visual functioning scale scores by categories of vision impairment considering both the betterseeing eye and worse-seeing eye of the German populationbased Gutenberg Health Study (GHS), 2007-2012

\begin{tabular}{|c|c|c|c|c|}
\hline & & \multicolumn{3}{|c|}{ Worse-seeing eye } \\
\hline & & $\begin{array}{l}\text { No VI }(n= \\
11,021)\end{array}$ & $\begin{array}{l}\text { Mild VI }(n= \\
465)\end{array}$ & $\begin{array}{l}\text { Moderate/ } \\
\text { severe VI }(n= \\
455)\end{array}$ \\
\hline \multirow[t]{3}{*}{$\begin{array}{l}\text { Better- } \\
\text { seeing } \\
\text { eye }\end{array}$} & No Vl & $\begin{array}{l}89.6(81.4 / \\
95.1), n= \\
11,021\end{array}$ & $\begin{array}{l}84.0(74.9 / \\
89.6), n= \\
430\end{array}$ & $\begin{array}{l}80.5(68.0 / 89.5) \\
n=395\end{array}$ \\
\hline & Mild VI & / & $\begin{array}{l}70.2(62.5 / \\
80.2), n=35\end{array}$ & $\begin{array}{l}66.8(45.7 / 76.0) \\
n=34\end{array}$ \\
\hline & $\begin{array}{l}\text { Moderate/ } \\
\text { severe VI }\end{array}$ & / & / & $\begin{array}{l}63.2(46.6 / 78.7) \\
n=26\end{array}$ \\
\hline
\end{tabular}

Scores displayed as medians (interquartile range), VI Vision impairment; no VI: $<0.32$ logMAR, mild VI: 0.32-0.5 logMAR; moderate/severe VI: > 0.5 logMAR

Participants with no visual impairment in the better-seeing eye and mild visual impairment in the fellow eye had a 1.9-point lower SES score than participants with no visual impairment in both eyes. Participants with no visual impairment in the better-seeing eye and severe visual impairment in the fellow eye had a 5.7-point lower SES score than participants with no visual impairment in both eyes (95\% CI -6.4; - 5.0). These estimates were from the regression model adjusted for age, sex and socioeconomic status (Table 7). The regression results also showed a substantial contribution of both eyes on SES. Adjustment for different potential confounders and excluding general comorbidities did not substantially change the regression estimates. In the subsample without amblyopia, the influence of a worse-seeing eye with moderate/severe VI in addition to a better-seeing eye with no VI was larger than that in the whole sample, and the effect size was similar to mild VI in both eyes (Additional files 2, 3, 4, 5, 6 and 7). For all regression coefficients in the main analyses, $\mathrm{p}$ was below 0.0001 .

In addition to adjusting for age, we calculated separate regression models for participants aged younger than 65

Table 5 NEI VFQ-25 socioemotional scale scores by categories of vision impairment (by the better-seeing eye and worseseeing eye) of the German population-based Gutenberg Health Study (GHS), 2007-2012

\begin{tabular}{|c|c|c|c|c|}
\hline & & \multicolumn{3}{|c|}{ Worse-seeing eye } \\
\hline & & $\begin{array}{l}\text { No VI }(n= \\
11,021)\end{array}$ & $\begin{array}{l}\text { Mild VI }(n= \\
465)\end{array}$ & $\begin{array}{l}\text { Moderate/ } \\
\text { severe VI }(n= \\
455)\end{array}$ \\
\hline \multirow{3}{*}{$\begin{array}{l}\text { Better- } \\
\text { seeing } \\
\text { eye }\end{array}$} & No VI & $\begin{array}{l}100(95.1 / 100) \\
n=11,021\end{array}$ & $\begin{array}{l}97.1(91.2 / \\
100), n=430\end{array}$ & $\begin{array}{l}94.1(85.8 / 100), \\
n=395\end{array}$ \\
\hline & Mild VI & / & $\begin{array}{l}90.1(72.4 / \\
97.1), n=35\end{array}$ & $\begin{array}{l}73.7(67.5 / 95.2) \\
n=34\end{array}$ \\
\hline & $\begin{array}{l}\text { Moderate/ } \\
\text { severe VI }\end{array}$ & / & / & $\begin{array}{l}76.3(68.0 / 93.9) \\
n=26\end{array}$ \\
\hline
\end{tabular}

Scores displayed as medians (interquartile range); VI Vision impairment; no Vl: $<0.32$ logMAR, mild Vl: 0.32-0.5 logMAR; moderate/severe Vl: > 0.5 logMAR) years and those aged 65 years and older. In the younger group, the impact of VI on VFS scores was higher; in both age groups, there was a substantial difference in VFS scores between categories defined by VI of both eyes. For the SES score, the decrease in the groups including the better-seeing eye without visual impairment was larger in the older participants. In the other VI groups, the reduction was more substantial in the younger age group (Additional files 2, 3, 4, 5, 6 and 7).

\section{Discussion}

This study showed that the visual acuity of the worse-seeing eye has an important impact on VRQoL in addition to the impact of the better-seeing eye. In a large population-based setting, we showed the additional influence of the worse-seeing eye on VRQoL measured by the most commonly used VRQoL instrument, the NEI VFQ-25. The "one-eye approach", although common, is very likely to neglect the patient's perspective. Our results are in line with previous studies. Finger et al. used the same VI categories to evaluate the impact of the visual impairment of both eyes on patient-reported preferences but did use two other instruments instead of the NEI VFQ-25. There was no effect captured by generic EQ-5D, but the worse-seeing eye had an additional impact on the Vision and Quality of Life Index [4]. Varma et al. showed, in 5270 participants of the Los Angeles Latino Eye Study, that the impacts of unilateral moderate/severe VI and bilateral mild VI on VRQoL were similar, considering that only VI of one eye would have underestimated the real impact [31]. Hirneiss et al. reviewed the influence of both eyes on VRQoL in the context of treatment decisions based on 47 publications [3]. Despite the heterogeneity in study designs and methods applied to assess VRQoL, the authors conclude that treatment of both the better-seeing and worse-seeing eye leads to a benefit in the patients' quality of life, contrary to the common assumption that the better-seeing eye mostly determines VRQoL [3]. There is evidence that, in age-related macular degeneration (AMD), VRQoL is lower in subjects with both eyes affected than in unilateral affected subjects. Dong et al. estimated a difference of six points between both groups when analyzing the NEI VFQ-25 scores [8]. Treatment of AMD leads to an improvement of VRQoL, as shown with the NEI VFQ-25 questionnaire, regardless of whether the better-seeing or worse-seeing eye was treated [32-34]. For cataract surgery, multiple studies reported an increase of VRQoL in subjects after cataract surgery of the second eye [6, 35, 36]. Schuster et al. used Rasch-transformed NEI VFQ-25 data from the GHS and reported that VRQoL has a similar magnitude in bilateral phakic and pseudophakic subjects, but monolateral pseudophakic subjects have a 6-point lower VRQoL [37]. These results underline the importance of considering both eyes when assessing the impact of VI on patient-reported outcomes. 


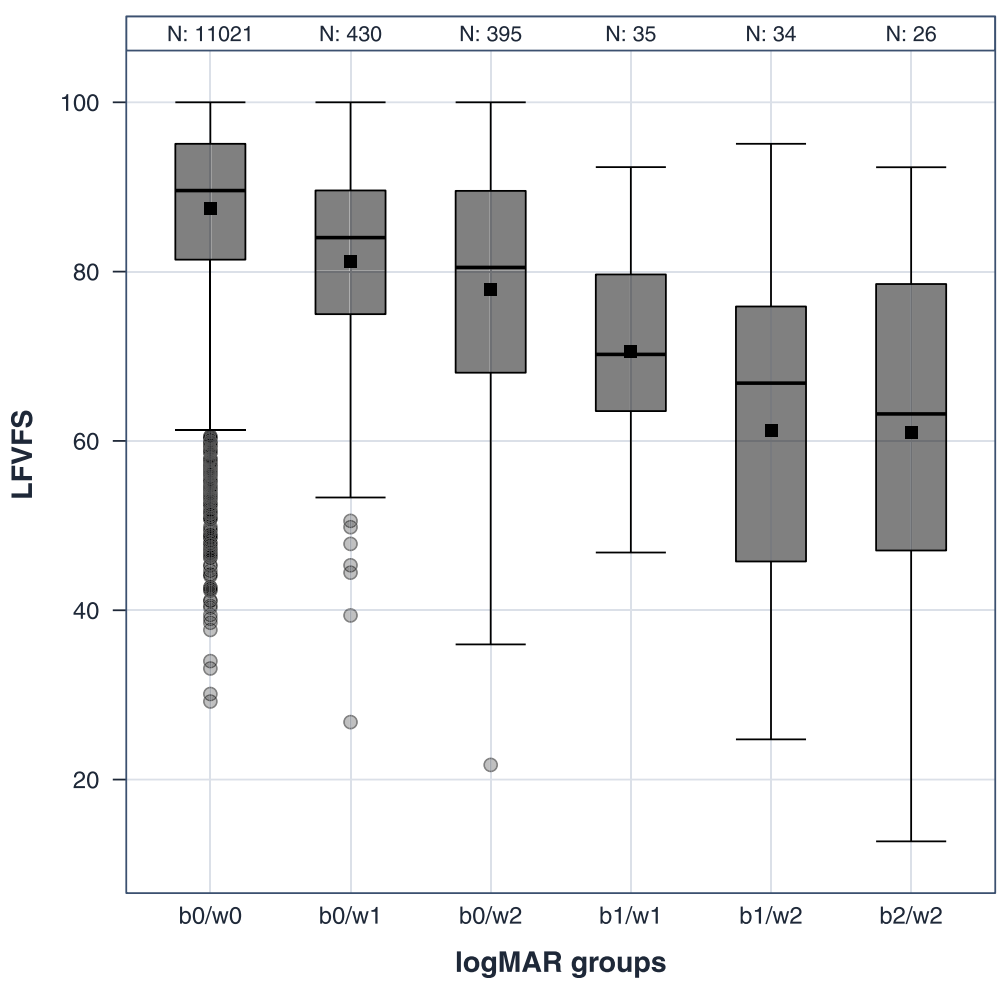

Fig. 1 Distribution of NEI VFQ-25 visual functioning scale scores by categories of vision impairment (by the better-seeing eye and worse-seeing eye) of the German population-based Gutenberg Health Study (GHS), 2007-2012. b: better-seeing eye; w: worse-seeing eye; 0: no visual impairment (<0.32 logMAR), 1: mild vision impairment (0.32-0.5 logMAR); 2: moderate/severe vision impairment (>0.5 logMAR); gray boxes: interquartile range (IQR); black line: median; black square: mean; whiskers: lowest data point still within 1.5 (IQR) of the lower quartile, and the highest data point still within 1.5 IQR of the upper quartile; dots: outliers

Table 6 Linear regression estimates of the influence of both the better-seeing and worse-seeing eyes on the NEI VFQ-25 visual functioning scale score in the German population-based Gutenberg Health Study (GHS), 2007-2012

\begin{tabular}{|c|c|c|}
\hline \multirow{2}{*}{$\begin{array}{l}\text { Category of visual impairment } \\
\text { considering better-seeing and } \\
\text { worse-seeing eye }\end{array}$} & \multirow{2}{*}{$\begin{array}{l}\text { Model } 1 \mathrm{a} \\
(n=11,941 \\
\left.\mathrm{R}^{2}=0.12\right)\end{array}$} & \multirow{2}{*}{$\begin{array}{l}\text { Model } 1 \mathrm{~b} \\
(n=11,889 \\
\left.\mathrm{R}^{2}=0.12\right)\end{array}$} \\
\hline & & \\
\hline & Estimate $(\mathrm{Cl})$ & Estimate $(\mathrm{Cl})$ \\
\hline \multirow[t]{2}{*}{ BE no Vl, WE mild VI } & $-5.2^{\mathrm{a}}$ & $-5.0^{\mathrm{a}}$ \\
\hline & $(-6.1 ;-4.2)$ & $(-6.0 ;-4.1)$ \\
\hline \multirow[t]{2}{*}{ BE no VI, WE moderate/ severe VI } & $-9.03^{\mathrm{a}}$ & $-9.01^{\mathrm{a}}$ \\
\hline & $(-10.0 ;-8.0)$ & $(-10.0 ;-8.0)$ \\
\hline \multirow[t]{2}{*}{ BE mild VI \& WE mild VI } & $-14.3^{\mathrm{a}}$ & $-14.5^{\mathrm{a}}$ \\
\hline & $(-17.6 ;-11.0)$ & $(-17.8 ;-11.1)$ \\
\hline \multirow{2}{*}{$\begin{array}{l}\text { BE mild VI \& WE moderate/ severe } \\
\text { VI }\end{array}$} & $-24.3^{\mathrm{a}}$ & $-24.1^{\mathrm{a}}$ \\
\hline & $(-27.7 ;-21.0)$ & $(-27.4 ;-20.8)$ \\
\hline \multirow{2}{*}{$\begin{array}{l}\mathrm{BE} \text { moderate/ severe VI, WE } \\
\text { moderate/ severe } \mathrm{VI}\end{array}$} & $-25.3^{\mathrm{a}}$ & $-24.4^{\mathrm{a}}$ \\
\hline & $(-29.1 ;-21.5)$ & $(-28.3 ;-20.5)$ \\
\hline
\end{tabular}

$B E$ Better-seeing eye, WE Worse-seeing eye, VI Vision impairment; no Vl: $<0.32$ logMAR, mild VI: 0.32-0.5 logMAR; moderate/severe VI: > 0.5 logMAR); all models adjusted for age and sex using both eyes with no VI as a reference; model $1 \mathrm{~b}$ additionally adjusted for socioeconomic status; $\mathrm{Cl}$ : $95 \%$ confidence interval; ${ }^{\text {a }}: p<0.0001, \mathrm{R}^{2}$ : adjusted $\mathrm{R}^{2}$
Table 7 Linear regression estimates of the influence of both the better-seeing and worse-seeing eyes on the NEI VFQ-25 socioemotional scale score in the German population-based Gutenberg Health Study (GHS), 2007-2012

\begin{tabular}{|c|c|c|}
\hline \multirow{2}{*}{$\begin{array}{l}\text { Category of visual impairment } \\
\text { considering better-seeing and } \\
\text { worse-seeing eye }\end{array}$} & \multirow{2}{*}{$\begin{array}{l}\text { Model } 1 \mathrm{a} \\
(n=11,941 \\
\left.\mathrm{R}^{2}=0.09\right)\end{array}$} & \multirow{2}{*}{$\begin{array}{l}\text { Model } 1 \mathrm{~b} \\
(n=11,889 \\
\left.\mathrm{R}^{2}=0.09\right)\end{array}$} \\
\hline & & \\
\hline & Estimate $(\mathrm{Cl})$ & Estimate $(\mathrm{Cl})$ \\
\hline \multirow[t]{2}{*}{ BE no VI, WE mild VI } & $-2.0^{\mathrm{a}}$ & $-1.9^{\mathrm{a}}$ \\
\hline & $(-2.6 ;-1.3)$ & $(-2.6 ;-1.2)$ \\
\hline \multirow[t]{2}{*}{ BE no VI, WE mild VI } & $-5.7^{\mathrm{a}}$ & $-5.7^{\mathrm{a}}$ \\
\hline & $(-6.4 ;-5.0)$ & $(-6.4 ;-5.0)$ \\
\hline \multirow[t]{2}{*}{ BE mild VI \& WE mild VI } & $-10.4^{\mathrm{a}}$ & $-9.6^{\mathrm{a}}$ \\
\hline & $(-12.8 ;-8.1)$ & $(-12.0 ;-7.2)$ \\
\hline \multirow{2}{*}{$\begin{array}{l}\text { BE mild VI \& WE moderate/ severe } \\
\text { VI }\end{array}$} & $-16.0^{\mathrm{a}}$ & $-15.9^{\mathrm{a}}$ \\
\hline & $(-18.4 ;-13.6)$ & $(-18.3 ;-13.5)$ \\
\hline \multirow{2}{*}{$\begin{array}{l}\mathrm{BE} \text { moderate/ severe } \mathrm{VI}, \mathrm{WE} \\
\text { moderate/ severe } \mathrm{VI}\end{array}$} & $-20.9^{a}$ & $-19.8^{a}$ \\
\hline & $(-23.6 ;-18.2)$ & $(-22.6 ;-17.1)$ \\
\hline
\end{tabular}

$B E$ Better-seeing eye, WE Worse-seeing eye, VI Vision impairment; no VI: $<0.32$ logMAR, mild VI: 0.32-0.5 logMAR; moderate/severe VI: > 0.5 logMAR; all models adjusted for age and sex using both eyes with no $\mathrm{VI}$ as reference; model $1 \mathrm{~b}$ additionally adjusted for socioeconomic status; $\mathrm{Cl}$ : $95 \%$ confidence interval; ${ }^{a}: p<0.0001, \mathrm{R}^{2}$ : adjusted $\mathrm{R}^{2}$ 


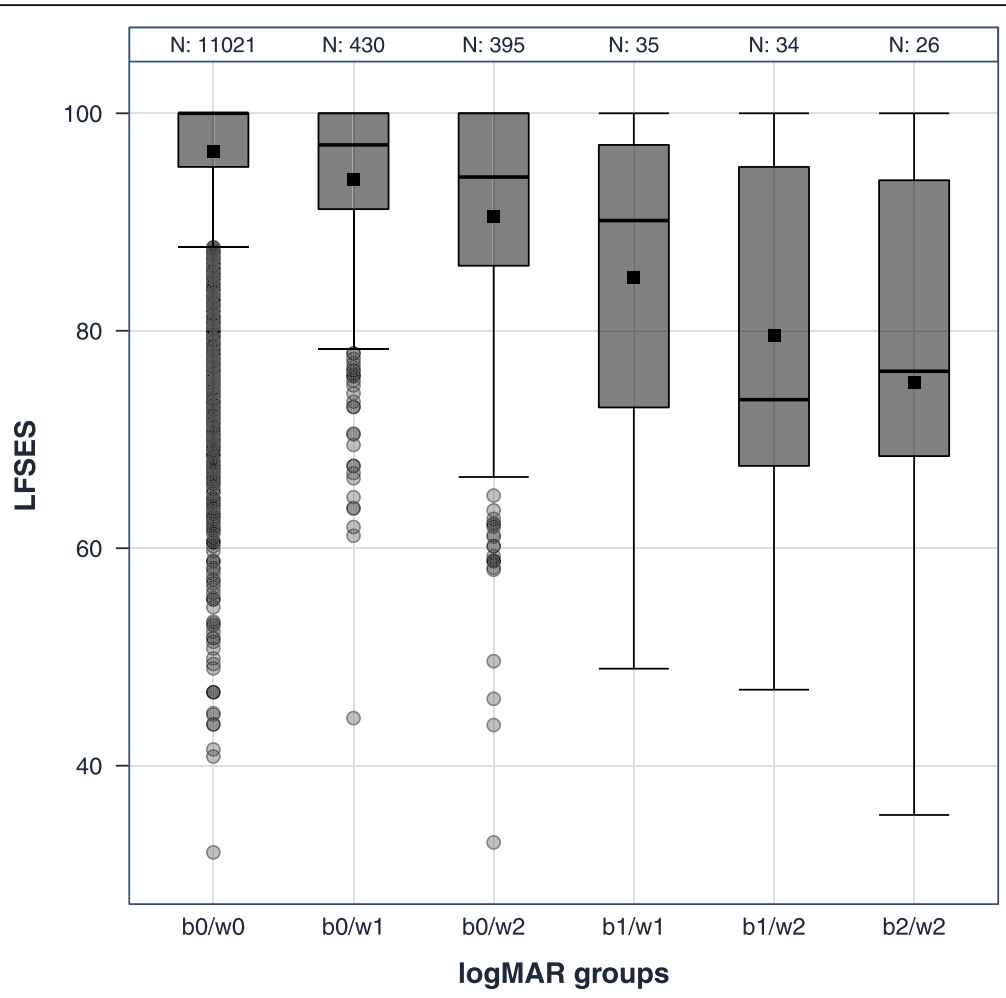

Fig. 2 Distribution of NEI VFQ-25 socioemotional scale scores by categories of vision impairment (by better-seeing eye and worse-seeing eye) of the German population-based Gutenberg Health Study (GHS), 2007-2012. b: better-seeing eye; w: worse-seeing eye; 0: no vision impairment (< $0.32 \log M A R), 1$ : mild vision impairment (0.32-0.5 logMAR); 2 : moderate/severe vision impairment ( $>0.5$ logMAR); gray boxes: interquartile range (IQR); black line: median; black square: mean; whiskers: lowest data point still within 1.5 (IQR) of the lower quartile, and the highest data point still within 1.5 IQR of the upper quartile; dots: outliers

There is no minimal clinically important difference (MCID) for Rasch-transformed NEI VFQ-25 scores; however, because the scale range is similar to the traditional scale ranges (both $0-100$ points), the MCID magnitude is expected to be similar. The MCID for traditional NEI VFQ-25 scores is estimated to be four to six points [38, 39].

The strengths of our study are the large sample size combined with the population-based sampling. The broad assessment of phenotype information is based on a standardized study design and quality controls. Despite the population-based sampling, individuals with bilateral visual impairment are likely to be underrepresented in the GHS cohort because of their lower likelihood to participate. Furthermore, we had a considerable share of participants who did not complete the NEI VFQ-25. At the beginning of the GHS, participants were asked to complete the questionnaire at home. This was then changed to an on-site procedure that greatly increased the rate of participation. Participants with missing NEI VFQ-25 had a reduced physical health, but this seems to be mostly related to general health and less to self-reported eye diseases and ocular parameters [19]. Therefore, we assume the bias due to missing information on VRQoL to be small. Additionally, the numbers in the groups with advanced stages or VI are low, and most participants had no VI. This was to be expected, given the low prevalence of VI in European populations below the age of 75 years and in our population-based study sample [40]. This leads to a reduced precision of the estimates in the groups with advanced stages of VI. Nevertheless, we could show an additional impact on VRQoL of the worse-seeing eye compared with considering the better-seeing eye only. Because the GHS includes a recall every 5 years, we are planning to rerun the analyses in a 10-year older population in the future, where we expect a higher prevalence in VI and to see even more distinct results.

\section{Conclusion}

In summary, we demonstrate in a large populationbased study that the visual acuity of the worse-seeing eye has an important impact on VRQoL, in addition to the impact of the better-seeing eye. Whenever possible, the function of both eyes should be considered in medical decision making, as well as in clinical, health care and public health research. 


\section{Additional files}

Additional file 1: Table S1. Characteristics of the study sample of the German population-based Gutenberg Health Study (GHS) with the visual acuity of both eyes and NEI VFQ-25 data available, stratified by sex. (PDF $219 \mathrm{~kb}$ )

Additional file 2: Table S2a. Linear regression estimates of the influence of both the better-seeing and worse-seeing eyes on the NEI VFQ-25 visual functioning scale score in the German population-based Gutenberg Health Study (GHS), 2007-2012, restricted to participants without chronic diseases or amblyopia. (PDF $218 \mathrm{~kb}$ )

Additional file 3: Table S2b. Linear regression estimates of the influence of both the better-seeing and worse-seeing eyes on the NEI VFQ-25 socioemotional scale score in the German population-based Gutenberg Health Study (GHS), 2007-2012, restricted to participants without chronic diseases or amblyopia. (PDF $218 \mathrm{~kb}$ )

Additional file 4: Table S3a. Linear regression estimates of the influence of both the better-seeing and worse-seeing eyes on the NEI VFQ-25 visual functioning scale score in the German population-based Gutenberg Health Study (GHS), 2007-2012, restricted to participants aged younger than 65 years. (PDF $215 \mathrm{~kb}$ )

Additional file 5: Table S3b. Linear regression estimates of the influence of both the better-seeing and worse-seeing eyes on the NEI VFQ-25 visual functioning scale score in the German population-based Gutenberg Health Study (GHS), 2007-2012, restricted to participants aged 65 years and older. (PDF $215 \mathrm{~kb}$ )

Additional file 6: Table S4a. Linear regression estimates of the influence of both the better-seeing and worse-seeing eye on the NEl VFQ-25 socioemotional scale score in the German population-based Gutenberg Health Study (GHS), 2007-2012, restricted to participants aged younger than 65 years. (PDF $215 \mathrm{~kb}$ )

Additional file 7: Table S4b. Linear regression estimates of the influence of both the better-seeing and worse-seeing eyes on the NE VFQ-25 socioemotional scale score in the German population-based Gutenberg Health Study (GHS), 2007-2012, restricted to participants aged 65 years and older. (PDF $215 \mathrm{~kb}$ )

\section{Abbreviations}

BSE: Better-seeing eye; Cl: Confidence interval; GHS: Gutenberg health study; NEI VFQ-25: National Eye Institute 25-item visual function questionnaire; QoL: Quality of life; SES: Socioemotional scale; VFS: Visual functioning scale; VRQoL: Vision-related QoL; WSE: Worse-seeing eye

\section{Acknowledgements}

We thank all study participants for their willingness to provide data for this research project, and we are indebted to all coworkers for their enthusiastic commitment.

\section{Funding}

The Gutenberg Health Study is funded through the government of Rhineland-Palatinate ("Stiftung Rheinland-Pfalz für Innovation", contract AZ 961-386261/733), the research programs "Wissen schafft Zukunft" and "Center for Translational Vascular Biology (CTVB)" of the Johannes GutenbergUniversity of Mainz, and its contracts with Boehringer Ingelheim and PHILIPS Medical Systems, including unrestricted grants for the Gutenberg Health Study. Schuster AK holds the professorship for ophthalmic healthcare research donated by "Stiftung Auge" and financed by "Deutsche Ophthalmologische Gesellschaft" and "Berufsverband der Augenärzte Deutschland e.V." He received research funding from Bayer Vital, Novartis and Heidelberg Engineering. Pfeiffer $\mathrm{N}$ received financial support and grants from Novartis, Ivantis, Santen, Thea, Boehringer Ingelheim Deutschland GmbH \& Co. KG, Alcon, Sanoculis; Nickels $S$ received reimbursement of travel expenses from Heidelberg Engineering $\mathrm{GmbH}$; Beutel ME received speaker honoraria from Pfizer Deutschland $\mathrm{GmbH}$, Shire Deutschland $\mathrm{GmbH}$ and currently receives research grants from the governments of Rhineland-Palatinate and NordrheinWestfalen, the German Association of Psychoanalysis and Psychotherapy (DGPT), the German Research Foundation, the German Ministry of Research, the German Cancer Aid and the European Union.

\section{Availability of data and materials}

The analysis presents clinical data of a large-scale population-based cohort with ongoing follow-up examinations. This project constitutes a major scientific effort with high methodological standards and detailed guidelines for analysis and publication to ensure scientific analyses on the highest level. Therefore, the data are not made available for the scientific community outside the established and controlled workflows and algorithms. To meet the general idea of the verification and reproducibility of scientific findings, we offer access to data at the local database in accordance with the ethics vote upon request at any time. The GHS steering committee, which comprises a member of each involved department and the coordinating principal investigator of the Gutenberg Health Study (PSW), convenes once a month. The steering committee decides on internal and external access of researchers and the use of the data and biomaterials based on a research proposal to be supplied by the researcher. Interested researchers make their requests to the coordinating principal investigator of the Gutenberg Health Study (Philipp S. Wild; philipp.wild@unimedizin-mainz.de). More detailed contact information is available at the homepages of the GHS (www.gutenberghealthstudy.org) or ophthalmic branch of the GHS (www.unimedizin-mainz.de/augenklinik/ forschung/gutenberg-gesundheitsstudie.html).

\section{Authors' contributions}

SN, AKS, RF, and NP conceived and designed the study. SN, AKS, AS, RF, NP analyzed and interpreted the data. SN, AKS, RF, and NP wrote the paper. All authors revised the manuscript critically and approved the final version.

\section{Ethics approval and consent to participate}

The study protocol and study documents were approved by the local ethics committee of the Medical Chamber of Rhineland-Palatinate, Germany (reference no. 837.020.07; original vote: 22.3.2007, latest update: 20.10.2015). According to the tenets of the Declaration of Helsinki, written informed consent was obtained from all participants prior to entering the study.

\section{Consent for publication}

Not applicable.

\section{Competing interests}

The authors declare that they have no competing interests.

\section{Publisher's Note}

Springer Nature remains neutral with regard to jurisdictional claims in published maps and institutional affiliations.

\section{Author details}

${ }^{1}$ Department of Ophthalmology, University Medical Center of the Johannes Gutenberg-University Mainz, Langenbeckstr. 1, 55131 Mainz, Germany. ${ }^{2}$ Preventive Cardiology and Preventive Medicine, Center for Cardiology, Cardiology I, University Medical Center of the Johannes Gutenberg-University Mainz, Mainz, Germany. ${ }^{3}$ Center for Cardiology, Cardiology I, University Medical Center of the Johannes Gutenberg-University Mainz, Mainz, Germany. ${ }^{4}$ Department of Psychosomatic Medicine and Psychotherapy, University Medical Center of the Johannes Gutenberg-University Mainz, Mainz, Germany. ${ }^{5}$ Institute for Medical Biostatistics, Epidemiology and Informatics, University Medical Center of the Johannes Gutenberg-University Mainz, Mainz, Germany. 'Department of Ophthalmology, University of Bonn, Bonn, Germany.

Received: 14 December 2018 Accepted: 13 May 2019

Published online: 06 June 2019

\section{References}

1. Bourne R, Price H, Taylor H, Leasher J, Keeffe J, Glanville J, Sieving PC, Khairallah M, Wong TY, Zheng Y, et al. New systematic review methodology for visual impairment and blindness for the 2010 global burden of disease study. Ophthalmic Epidemiol. 2013;20:33-9.

2. Bourne RRA, Flaxman SR, Braithwaite T, Cicinelli MV, Das A, Jonas JB, Keeffe J, Kempen JH, Leasher J, Limburg H, et al. Magnitude, temporal trends, and projections of the global prevalence of blindness and distance and near vision impairment: a systematic review and metaanalysis. Lancet Glob Health. 2017;5:e888-97. 
3. Hirneiss $\mathrm{C}$. The impact of a better-seeing eye and a worse-seeing eye on vision-related quality of life. Clin Ophthalmol. 2014;8:1703-9.

4. Finger RP, Fenwick E, Hirneiss CW, Hsueh A, Guymer RH, Lamoureux EL, Keeffe JE. Visual impairment as a function of visual acuity in both eyes and its impact on patient reported preferences. PLoS One. 2013;8:e81042.

5. Vu HT, Keeffe JE, McCarty CA, Taylor HR. Impact of unilateral and bilateral vision loss on quality of life. Br J Ophthalmol. 2005;89:360-3.

6. Lundstrom M, Stenevi U, Thorburn W. Quality of life after first- and secondeye cataract surgery: five-year data collected by the Swedish National Cataract Register. J Cataract Refract Surg. 2001;27:1553-9.

7. Javitt JC, Brenner MH, Curbow B, Legro MW, Street DA. Outcomes of cataract surgery. Improvement in visual acuity and subjective visual function after surgery in the first, second, and both eyes. Arch Ophthalmol. 1993;111:686-91.

8. Dong LM, Childs AL, Mangione CM, Bass EB, Bressler NM, Hawkins BS, Marsh MJ, Miskala P, Jaffee HA, McCaffrey LA. Health- and vision-related quality of life among patients with choroidal neovascularization secondary to age-related macular degeneration at enrollment in randomized trials of submacular surgery: SST report no. 4. Am J Ophthalmol. 2004;138:91-108.

9. Wild PS, Zeller T, Beutel M, Blettner M, Dugi KA, Lackner KJ, Pfeiffer N, Munzel T, Blankenberg S. The Gutenberg Health Study. Bundesgesundheitsblatt Gesundheitsforschung Gesundheitsschutz. 2012:55:824-9.

10. Höhn R, Kottler U, Peto T, Blettner M, Munzel T, Blankenberg S, Lackner KJ, Beutel M, Wild PS, Pfeiffer N. The ophthalmic branch of the Gutenberg health study: study design, cohort profile and self-reported diseases. PLoS One. 2015;10:e0120476.

11. Mangione CM, Lee PP, Gutierrez PR, Spritzer K, Berry S, Hays RD. Development of the 25-item National eye Institute visual function questionnaire. Arch Ophthalmol. 2001;119:1050-8.

12. Franke $\mathrm{GH}$, Esser J, Voigtländer A, Mähner N. Der National Eye Institute Visual Function Questionnaire (NEI-VFQ)-Erste Ergebnisse zur psychometrischen Überprüfung eines Verfahrens zur Erfassung der Lebensqualität bei Sehbeeinträchtigten. Z Med Psychol. 1998;7:178-84.

13. Hirneiss C, Schmid-Tannwald C, Kernt M, Kampik A, Neubauer AS. The NEI VFQ-25 vision-related quality of life and prevalence of eye disease in a working population. Graefes Arch Clin Exp Ophthalmol. 2010;248:85-92.

14. Wolfram C, Lorenz K, Breitscheidel L, Verboven Y, Pfeiffer N. Health- and vision-related quality of life in patients with ocular hypertension or primary open-angle glaucoma. Ophthalmologica. 2013;229:227-34.

15. Bertelmann T, Feltgen N, Scheffler M, Hufenbach U, Wiedon A, Wilhelm H, Ziemssen F. Vision-related quality of life in patients receiving intravitreal ranibizumab injections in routine clinical practice: baseline data from the German OCEAN study. Health Qual Life Outcomes. 2016;14:132.

16. Finger RP, Wiedemann P, Blumhagen F, Pohl K, Holz FG. Treatment patterns, visual acuity and quality-of-life outcomes of the WAVE study - a noninterventional study of ranibizumab treatment for neovascular agerelated macular degeneration in Germany. Acta Ophthalmol. 2013;91:540-6.

17. Renieri G, Pitz S, Pfeiffer N, Beutel ME, Zwerenz R. Changes in quality of life in visually impaired patients after low-vision rehabilitation. Int J Rehabil Res. 2013;36:48-55.

18. Pesudovs K, Gothwal VK, Wright T, Lamoureux EL. Remediating serious flaws in the National eye Institute visual function questionnaire. J Cataract Refract Surg. 2010;36:718-32.

19. Nickels S, Schuster AK, Singer S, Wild PS, Laubert-Reh D, Schulz A, Finger RP, Michal M, Beutel ME, Munzel T, et al. The National eye Institute 25-item visual function questionnaire (NEI VFQ-25) - reference data from the German population-based Gutenberg health study (GHS). Health Qual Life Outcomes. 2017;15:156.

20. Khadka J, McAlinden C, Pesudovs K. Quality assessment of ophthalmic questionnaires: review and recommendations. Optom Vis Sci. 2013;90:720-44.

21. Labiris G, Katsanos A, Fanariotis M, Tsirouki T, Pefkianaki M, Chatzoulis D, Tsironi E. Psychometric properties of the Greek version of the NEI-VFQ 25. BMC Ophthalmol. 2008;8:4

22. Kovac B, Vukosavljevic M, Djokic Kovac J, Resan M, Trajkovic G, Jankovic J, Smiljanic M, Grgurevic A. Validation and cross-cultural adaptation of the National eye Institute visual function questionnaire (NEI VFQ-25) in Serbian patients. Health Qual Life Outcomes. 2015:13:142.

23. Mollazadegan K, Huang J, Khadka J, Wang Q, Yang F, Gao R, Pesudovs K. Cross-cultural validation of the National eye Institute visual function questionnaire. J Cataract Refract Surg. 2014;40:774-84.
24. Brosel D, Sabel BA, Franke GH, Gall C. The 2-scale model of the National eye Institute visual function questionnaire (NEI-VFQ) to assess vision-related quality of life. Klin Monatsbl Augenheilkd. 2017;234:719-25.

25. Petrillo J, Cano SJ, McLeod LD, Coon CD. Using classical test theory, item response theory, and Rasch measurement theory to evaluate patientreported outcome measures: a comparison of worked examples. Value Health. 2015;18:25-34.

26. Dougherty BE, Bullimore MA. Comparison of scoring approaches for the NEI VFQ-25 in low vision. Optom Vis Sci. 2010;87:543-8.

27. Lampert T, Kroll LE, Muters S, Stolzenberg H. Measurement of the socioeconomic status within the German Health Update 2009 (GEDA). Bundesgesundheitsblatt Gesundheitsforschung Gesundheitsschutz. 2013;56:131-43.

28. Holladay JT. Proper method for calculating average visual acuity. J Refract Surg. 1997;13:388-91.

29. Elflein HM. Amblyopia. Epidemiology, causes and risk factors. Ophthalmologe. 2016;113:283-8.

30. Core R. Team: R: a language and environment for statistical computing. Vienna: R Foundation for Statistical Computing; 2016.

31. Varma R, Wu J, Chong K, Azen SP, Hays RD. Impact of severity and bilaterality of visual impairment on health-related quality of life. Ophthalmology. 2006;113:1846-53.

32. Bressler NM, Chang TS, Suner IJ, Fine JT, Dolan CM, Ward J, lanchulev T. Vision-related function after ranibizumab treatment by better- or worseseeing eye: clinical trial results from MARINA and ANCHOR. Ophthalmology. 2010;117:747-56 e744

33. Finger RP, Hoffmann AE, Fenwick EK, Wolf A, Kampik A, Kernt M, Neubauer AS, Hirneiss C. Patients' preferences in treatment for neovascular age-related macular degeneration in clinical routine. Br J Ophthalmol. 2012;96:997-1002.

34. Finger RP, Guymer RH, Gillies MC, Keeffe JE. The impact of anti-vascular endothelial growth factor treatment on quality of life in neovascular agerelated macular degeneration. Ophthalmology. 2014;121:1246-51.

35. Castells X, Comas M, Alonso J, Espallargues M, Martinez V, Garcia-Arumi J, Castilla M. In a randomized controlled trial, cataract surgery in both eyes increased benefits compared to surgery in one eye only. J Clin Epidemiol. 2006;59:201-7.

36. Elliott DB, Patla AE, Furniss M, Adkin A. Improvements in clinical and functional vision and quality of life after second eye cataract surgery. Optom Vis Sci. 2000;77:13-24.

37. Schuster AK, Pfeiffer N, Schulz A, Nickels S, Hohn R, Wild PS, Blettner M, Munzel T, Beutel ME, Lackner KJ, Vossmerbaeumer U. The impact of pseudophakia on vision-related quality of life in the general population the Gutenberg health study. Aging (Albany NY). 2017;9:1030-40.

38. Suner IJ, Kokame GT, Yu E, Ward J, Dolan C, Bressler NM. Responsiveness of NEI VFQ-25 to changes in visual acuity in neovascular AMD: validation studies from two phase 3 clinical trials. Invest Ophthalmol Vis Sci. 2009;50:3629-35.

39. Lloyd AJ, Loftus J, Turner M, Lai G, Pleil A. Psychometric validation of the visual function Questionnaire-25 in patients with diabetic macular edema. Health Qual Life Outcomes. 2013;11:10.

40. Delcourt C, Le Goff M, von Hanno T, Mirshahi A, Khawaja AP, Verhoeven VJM, Hogg RE, Anastosopoulos E, Cachulo ML, Hohn R, et al. The decreasing prevalence of nonrefractive visual impairment in older Europeans: a meta-analysis of published and unpublished data. Ophthalmology. 2018;125:1149-59.
Ready to submit your research? Choose BMC and benefit from:
- fast, convenient online submission
- thorough peer review by experienced researchers in your field
- rapid publication on acceptance
- support for research data, including large and complex data types
- gold Open Access which fosters wider collaboration and increased citations
- maximum visibility for your research: over $100 \mathrm{M}$ website views per year
At BMC, research is always in progress.
Learn more biomedcentral.com/submissions 